\title{
Themes and methodological issues in Court Interpreting research
}

\author{
Sandra Hale \\ University of Western Sydney
}

The field of Legal Interpreting encompasses a wide variety of contexts including police interviews and interrogations, lawyer-client conferences, tribunal and court hearings and trials. Most of the research carried out in the field to date has concentrated on the discourse of the courtroom in Common Law countries (Berk-Seligson 1988, 1990, 1999; Hale 1997b, 1999, 2004; Mason \& Stewart 2001; Pym, 1999; Rigney 1997). This is partly due to the availability of the data, as most courtrooms are open to the public, but also due to the vast amount of research conducted into the language of the courtroom, which has served as a theoretical basis for the study of court interpreting. These studies draw on discourse analysis, the ethnography of language, pragmatics, experimental psychology and forensic linguistics to inform their methods. Other research into legal interpreting has looked at other, non-linguistic aspects of the practice, such as role perceptions and expectations, using social science methods of surveys, interviews and focus groups (Fowler 1997; Kelly 2000; Hale \& Luzardo 1997; Angelelli 2004). Fewer studies have concentrated on the other aspects of legal interpreting, such as police interpreting (Krouglov 1999; Berk-Seligson 2000; Russell 2004; Wadensjö 1997) and tribunal hearings (Wadensjö 1992; Mason \& Stewart 2001; Barsky 1996). With the exception of a limited number of experimental studies (Berk-Seligson 1990 and Hale 2004) most legal interpreting research studies have been descriptive, qualitative and speculative, providing useful information on the current state of affairs but little on the impact such practices have on the legal process. This contribution will concentrate only on court interpreting research. It will review the major research projects to date, highlight their strengths and weaknesses, identify the gaps that exist in our knowledge of the field and propose further research studies to fill such gaps.

\section{Introduction}

The field of legal interpreting is wide and complex. Interpreters commonly work in all the tiers of the legal process, including police interviews and interrogations, lawyer-client conferences, tribunal hearings and court hearings and trials (see Benmaman 1995 for a description of legal interpreting). Such settings vary in level of formality, number of participants, and access to the public; factors which impact on the dynamics of the situation as well as on the accessibility of data for any potential research. The bulk of the linguistic micro-analytical empirical research conducted into legal interpreting has 
been in the context of the courtroom. The main reason for this is the public nature of court appearances, especially in Common Law countries. Most court cases are open to the public and hence permission to conduct research is more easily attainable. The other settings are regarded as confidential and therefore more difficult to access. This trend is not unique to legal interpreting. It is also the trend found in the general field of forensic linguistics, where the setting for the majority of the reported research is also the courtroom. This contribution will therefore concentrate on reviewing only the research on court interpreting, due to its limitations in length. It will firstly review the linguistic based research followed by the survey-based studies.

\section{The increased interest in court interpreting research}

Interest in researching court interpreting has increased in the last two decades, yet the volume remains very small in comparison to other disciplines. Eades, Hale \& Cooke (1999) suggest that the absence of compulsory pre-service training and the low levels of remuneration for practising interpreters hamper the development and maintenance of viable university academic programs in legal interpreting which would generate research. Hale (2004), in her review of Australian government reports on the provision of legal interpreting services, found that every report recommended adequate tertiary level training to improve the practice, but none made any mention of the need for research to inform the curricula and ultimately the practice. This perceived lack of awareness of the need for research in this field from those outside the profession, and the lack of interest from established researchers in related fields, have encouraged some practitioners to conduct practical, action research to answer questions encountered in their own practice. It is a characteristic feature of many of the researchers who investigate legal interpreting that they are currently or have been in the past, practising interpreters themselves. These researchers are intimately acquainted with the issues that surround legal interpreting and are driven to investigate aspects that require practical answers to real life problems. Therefore, the published research presents a range of themes that cover the most salient issues of the practice.

\section{Strengths and weaknesses in court interpreting research}

Such level of relevance to the practice, as well as the predominant use of authentic data in legal interpreting research, add strength to the validity of such studies. The vast majority of court interpreting research revolves around the collection of authentic interpreting data or of the opinions of the participants involved in interpreted interactions by way of interviews, focus groups or questionnaires; methodologies deriving mostly from discourse and conversation analysis and ethnography. Descriptive research is crucial in obtaining an understanding of the practice and in building a body of em- 
pirical evidence to complement existing anecdotal evidence, but while the validity of these studies may be high, their reliability may sometimes be questioned. Hasty assumptions and generalisations have tended to be extrapolated from studies with very small databases or from inconclusive results. There is the danger in community interpreting research to make vast generalisations about universal interpreting practices in the absence of detailed information about the background of the interpreters, the level and rigour of interpreting training acquired, if any, their language combination, or the frequency of the reported occurrences which lead to the conclusions. For instance, many qualitative studies use isolated examples to arrive at a number of conclusions, failing to inform the reader of the representativeness of such examples. Often it is only the instances of poor or inaccurate interpreting which are highlighted. The rationale behind this bias is generally to implement changes to improve the practice. However, the inexistence of studies which focus on examples of accurate interpreting has led many to conclude that accuracy of interpreting is unattainable. There is also very little research into the impact of adequate training on the practice. This is mainly due to the paucity of formal, adequate courses.

Another point to note is that authentic data-based research can only be speculative about the reasons behind interpreters' choices and their impact on the interaction. More experimental studies, using a combination of sound qualitative and quantitative methods of analysis, are needed to test the hypotheses raised by descriptive studies.

\section{Main issues in Court Interpreting research}

Anecdotal evidence has provided a number of premises about the practice of court interpreting. Morris (1999) summarises most of these in an article on the predicaments of court interpreting ${ }_{2}$ which presents the results of a canvassing study, combining a number of data sources including: personal observations, interviews with interpreters, lawyers and the judiciary, and published historical literature on court interpreting. In addition to the complexity of the interpreting process and of the difficulty in achieving an accurate rendition in a highly constrained speech activity type, numerous extra linguistic factors impinging on the practice of court interpreting are identified by Morris. These include: the disparate attitudes of those who speak through interpreters, their limited understanding of the meaning of accuracy, and their conflicting expectations of the interpreter's role; the physical setting of the court interpreter; the lack of quality control measures implemented by the court; the consequences of the inadequate treatment received by interpreters in the courtroom from all parties; the interpreter's dilemma in deciding when to intervene to offer clarifications of cross-cultural differences; and the stressful effects of such predicaments on interpreters as individuals. Some of these issues have been further addressed by other researchers, others remain to be investigated, as will be seen in the review that follows. 


\section{The language of the courtroom}

The late nineteen seventies and early 1970's saw a marked interest in the study of oral courtroom language, especially in Common Law countries, with the trend continuing to strengthen in the 1990's and the current decade (see e.g., Atkinson \& Drew 1979; Danet \& Bogoch 1980; O’Barr 1982; Conley \& O'Barr 1990; Gibbons 2003). Until that time, the majority of research into the language of the law had concentrated on written legal language. The innovative work into the oral discourse of the monolingual courtroom inspired other researchers to extend the results of such research into the study of the dynamics of the bilingual courtroom, where interpreters are an added participant. The new international journal Forensic Linguistics, established in the mid 1990's, incorporated Legal Interpreting as part of its discipline, with a number of articles published on the topic and a special issue dedicated to Legal Interpreting in 1999. John Gibbons' book entitled Forensic Linguistics published in 2003 also dedicates one chapter to legal interpreting and translation. Legal interpreting is therefore being recognised as an important area of research in the area of forensic linguistics.

The results of these early monolingual studies provided a deeper understanding of the significance of language in the courtroom, with a clear relevance to the practice of court interpreting. Among the most salient results are that lawyers use language strategically to achieve their own purposes in court, through a number of linguistic means; that jurors and the bench assess witnesses' credibility, trustworthiness, intelligence and competence, based not only on the content of their testimony but importantly also on the style of speech they use to present their evidence; and that power is exercised in the courtroom through language in a number of different ways. All of these results have major implications for the work of interpreters, as issues other than propositional content of the utterances are also of crucial importance to this setting. This higher awareness of the significance of subtle linguistic and extra linguistic features in the courtroom raised a number of questions for court interpreting about issues not previously considered to be important.

\subsection{The interpretation of question types}

One strategy used by lawyers to elicit the desired answers is the type of question used, which differs according to the type of examination. During 'examination-in-chief', witnesses are given more freedom to respond and hence less coercive question types are used. These include modal interrogatives and Wh-questions. In cross-examination, however, more coercive types of questions predominate, which include closed choice questions and leading questions, with different types of tags used with different pragmatic purposes (see Loftus 1979; Danet \& Bogoch 1980; Woodbury 1984; Walker, 1987; Maley \& Fahey 1991). Indeed, the aforementioned studies found 
that questions are used as a means of control in the courtroom and that changes to question types can have an impact on the answers they elicit. A number of researchers have conducted studies into the way interpreters understand and interpret courtroom questions.

Berk-Seligson (1990/2002, 1999), Rigney (1997, 1999), Hale (1999, 2001) and Fraser \& Freedgood (1999) all examine the treatment of courtroom questions by Spanish-English interpreters from a discourse analytical, pragmatic perspective. Berk-Seligson's ethnographic study of courtroom interpreting, conducted in the early 1980s and later reported in her book The Bilingual Courtroom in 1990/2002, was the first major data-based study of its kind. She recorded the performance of 18 interpreters in 114 hours of courtroom proceedings in the United States, which she later transcribed and analysed using discourse analytical, qualitative and quantitative research methods. She also used ethnographic methods of observation and interviews with lawyers and court interpreters, as well as experimental methods. The data were analysed from a number of different perspectives, answering a variety of research questions. With regards to the interpretation of questions, Berk-Seligson concluded that generally "the court interpreter affects the verbal outcome of attorneys' and judges' questions (...)" interfering "(...) with the attempts of examiners to get out their questions in the way they want to (...)" (1990: 25). A number of reasons contributed to this finding. Interpreters seemed completely unaware of the strategic use of questions and were more concerned with ensuring that the witness understood the propositional aspect of the question by modifying it, elaborating on it or adding extra information. They also seemed unaware of some of the other language strategies used by lawyers, especially cross-examiners, and interfered with them by unjustifiably interrupting, making their own observations or omitting important information. The example below illustrates one such instance.

Example 1:

Defense attorney:

Interpreter [addressing attorney]:

Defense attorney: [addressing interpreter]

(Berk-Seligson 2002:72).
What was his destination? I translated that, sir.

Try again.

In example 1, the interpreter attempts to help the lawyer to save time by alerting him to the fact that the question just put had already been translated. The lawyer, who was using repetition as a common strategy in cross-examination to emphasise a point or possibly elicit a contradictory answer, makes clear that the repetition was deliberate by asking the interpreter to "try again".

More recently, Berk-Seligson (1999) conducted a study of the way one interpreter dealt with leading questions in court, using a database of 504 leading questions. Leading questions are questions that state or suggest more than what they ask. They are a powerful tool used by cross-examiners to control the evidence they elicit from the other side's witnesses. 
The function of leading questions is to control the content of the information presented in cross-examination, as well as to challenge the other side's witnesses' version of the facts as presented in their evidence-in-chief. The way this is achieved is by choosing the appropriate type of question. Other researchers (Ogle et al. 1980; Woodbury 1984) have identified the following question types as leading: declaratives, declaratives with tags, polar interrogatives and forced choice questions. All of these types provide the witness with the suggested answer to the question, to which the witness has to agree or disagree. Above, the questions have been ordered in terms of their level of coerciveness, with the first two being considered the most coercive. In her 1999 study, Berk-Seligson set out to discover how accurately leading questions were interpreted by Spanish court interpreters in terms of their pragmatic force and level of coerciveness. She found that half of the questions in her sample were, surprisingly, interpreted inaccurately for the following two reasons: "(a) the tag, or other leading (i.e suggestive) portion of the question was omitted entirely in the interpretation, or (b) the nature of the question was changed, making it either more leading or less so" (Berk-Seligson 1999:39). Example 2 illustrates the type of change found by the study:

\section{Example 2}

Defence attorney: You made a report about this incident, did you not?

Interpreter:

¿Hizo usted un reporte de este incidente?

[Did you make a report about this incident?]

(Berk-Seligson 1999:45)

This example shows an instance of a reduction of the pragmatic force of the question, making it less coercive. Its force is greatly reduced. The tag is omitted thus changing a challenging, leading question into a genuine information-seeking question. Berk-Seligson aptly explains that there are difficulties associated with interpreting levels of coerciveness and that features other than the surface semantic and syntactic equivalence are to be considered. For example, the use of the personal pronoun in Spanish, intonation and pitch as well as the type of tag, all have an impact on the level of coerciveness. However, there is no justifiable reason for such marked changes in the interpretation as shown in example 2 . The only feasible explanation is that the interpreter was not concerned with the type of question but simply with maintaining its propositional content.

Using the data from the interpreted testimony of one witness by one interpreter in the O.J. Simpson trial, comprising a total of 964 questions, Rigney (1999) also studied the pragmatic alterations found in the interpreter's renditions. She found that $40.4 \%$ of all the Spanish interpretations presented some type of interpretation deviation, either due to content error (such as omissions, incorrect verb tense, etc) or to pragmatic alterations. She found that such pragmatic alterations were most common when interpreting tags and declaratives in particular, but also modal interrogatives to a lesser extent. Although some of these alterations seemed to have no logical 
explanations, some were due to a lack of direct semantic equivalence which matched the pragmatic force in both languages. In cases such as these, interpreters need to resort to extra resources in the target language to achieve the same pragmatic meaning and force, making their task more difficult.

Hale (2001) reports the results of a study of 13 Spanish-English court interpreters in NSW, Australia, comprising 1957 questions. She presents a comparative analysis of the differences found in the formulation of questions in English and Spanish to demonstrate that in order for a question to be interpreted in a pragmatically accurate way, it does not necessarily need to follow the same surface structure or contain the same grammatical elements. For example, the pragmatic force of Spanish questions depends not only on their grammatical structure but also on their thematic structure, on the use of the personal pronoun, on the level of markedness and on the use of intonation.

Corroborating Berk-Seligson's and Rigney's results, Hale found that declaratives and tags were the most problematic types of questions to interpret. Her study showed that interpreters omitted the tag $52.12 \%$ of the time. She attributes this high tendency to a number of reasons: interpreters' unawareness of their importance, their desire to shorten the interpretation to save the court's time, but also the lack of grammatical equivalence, which make their interpretation more difficult. A comparative analysis of English and Spanish tag questions demonstrates that the intonation of the English statement and tag is crucial in the understanding of their pragmatic meaning, and that this will determine the most pragmatically accurate way of rendering the English tag into Spanish. Hale shows that at times omitting the tag is the most pragmatically appropriate choice. One such example involves the interpretation of the positive constant polarity tag with a downward intonation in English. Such a tag expresses sarcastic suspicion and allows the questioner to probe (see Quirk et al. 1985, Maley \& Fahey 1991). Hale proposes that including a tag in the translation of this type of question in Spanish would be inaccurate, as all the tags in Spanish would not reflect such pragmatic force but would convert it into a genuine question of fact. For this type of tag, Hale proposes the use of an initial "So" (Así que), which is the version used by a number of interpreters in the sample. The three studies quoted above demonstrate that these types of questions cause problems in approximately $50 \%$ of all cases. This means, of course, that in $50 \%$ of the cases, these interpreters did not have any problems and interpreted the questions accurately, maintaining a pragmatic equivalence.

Hale (1999) conducted another study of courtroom questions which looked specifically at the use of discourse markers used by lawyers to preface their questions and at the way these were treated by Spanish-English interpreters. The data were generated by seventeen NSW Local Court cases interpreted by different interpreters. Hale found that the discourse markers "well", "now" and "you see" predominated as prefaces to lawyers' questions, and that these were used with different purposes according to whether they appeared in examination-in-chief or in cross-examination. In cross-examination these markers were mainly used as markers of argumentation and 
confrontation, increasing the level of coerciveness of questions and their pragmatic force. When used in examination-in-chief, with the exception of "you see" which only appeared in cross-examination, the two remaining markers were used to maintain control and coherence and at times to express frustration at the witnesses' inability to answer appropriately. These results were consistent with previous research of the use of these markers in monolingual conversation. Hale found that, unlike the results of the previous studies with regards to question type, when it came to discourse markers, interpreters omitted them almost systematically, a finding also corroborated by Fraser \& Freedgood (1999). Hale speculates that the two main reasons for this result are, firstly, an unawareness of their importance on the part of interpreters and, secondly, an inherent translation difficulty. Hale presents suggested pragmatic equivalents of these discourse markers according to context as a guide to practising interpreters.

All three researchers, Berk-Seligson, Rigney and Hale, conclude that these results strongly demonstrate interpreters' lack of awareness of the significance of the strategic use of courtroom language and of maintaining its pragmatic force in their interpretation. Such results have direct implications for training and certification or accreditation examinations.

The major strength of the studies reported above lies in their use of large data sets. Some not only in terms of hours of recorded authentic data but also in the number of interpreters involved, making the results more generalisable. Although some differences were found, the results mostly corroborate each other. The many common variables of these studies also add to their reliability. Whereas many other studies of interpreting involve ad hoc, unprofessional interpreters, even interpreters with a very limited bilingual competence, these analyse the performance of relatively competent Spanish-English interpreters, working in two countries where interpreters are generally required to pass a certification or accreditation examination, although very few have any formal interpreting training. The studies also use a good combination of qualitative and quantitative methods of analysis. There are, however, slight pragmatic differences between different varieties of Spanish that are not highlighted in them, and possibly differences of opinion between the different researchers about such variations. Further research into monolingual Spanish pragmatics would be useful in ascertaining the most pragmatically appropriate renditions. Another aspect to consider is that studies based on naturally occurring data cannot claim to prove the potential impact of the interpreter-induced changes on the listener. Experimental studies are needed to follow up on the speculations proposed by the authors, which should also extend to an investigation of the effect of adequate training on the performance of interpreters and on the feasibility of maintaining such high levels of accuracy. Finally, these studies should be replicated using data from other language combinations in order for the results to be more universally applicable.

Completely different challenges are faced by interpreters who deal with vastly disparate languages and cultures, such as traditional indigenous cultures. Cooke $(1995,1996,1998)$ reports the results of two ethnographic, 
discourse analytical studies of two different court cases where Aboriginal witnesses from the Australian Northern Territory were questioned. Three major issues are highlighted by Cooke. Firstly, the cultures are so disparate that many common concepts in either culture cannot be translated by equivalent concepts, but require detailed explanations, rather than translations. Although such a situation may arise with non-indigenous languages, it is not as common. Secondly, many Aborigines speak what on the surface appears to be fluent English. However, their version of English is pragmatically very different from Standard English, with much linguistic interference, making mutual understanding problematic. It is difficult in such situations to convince the court of the need for an interpreter. In such circumstances, the interpreter will interpret from Aboriginal English into Standard English and vice versa only when required. It will almost always be only the interpreter who is able to identify when such problems arise. Example 3 quotes an Aboriginal witness' justification for needing an interpreter, although his English seemed adequate from the point of view of the opposing counsel.

Example 3

Coroner:

Why do you want to use an interpreter just now?

Witness:

It's in connection that I - the subject - the subject changes and I

get confused. The interpreter can give a good explanation. There's different varieties of questions.

(Cooke 1995:63)

The third issue raised, refers to the different functions of questions in both cultures. Australian traditional Aboriginal cultures are not accustomed to being questioned. Questions are considered to be impolite and when confronted with them, Aboriginal witnesses have a propensity to agree with everything the questioner suggests, out of respect for authority, politeness or desire to please. This is what has been called "gratuitous concurrence" (see Liberman 1985; Eades 1992). Apart from cultural differences surrounding questioning, there are also linguistic differences that complicate the comprehension of questions. Specifically Cooke points to a number of question types that are characteristically problematic, creating dilemmas for interpreters when deciding how best to interpret them. Yes/No questions with embedded noun clauses such as "[a]nd you told them that the dead man was sick in the head?", cause confusion, as they present two different propositions. A native English speaker would respond to the main clause of the sentence. An Aboriginal speaker would respond to the veracity of the statement in the embedded clause (Cooke 1996:79). Another similar complication arises with negative questions such as shown in example 4.

Example 4

Counsel: But the old man didn't go in the boat, did he?

Witness:

Yes

Counsel:

I beg your pardon?

Witness:

Yes 
Interpreter: Yes, he's affirming that he didn't go in the boat.

(Cooke 995: 109)

This is not unique to Australian Aboriginal languages. Other languages share these assumptions. In those circumstances, interpreters need to change a positive to a negative question in the interpreted rendition, to match the intention rather than the words. This becomes impossible when the witness is giving evidence in English, as is the case here, and therefore the interpreter interrupts to clarify rather than to interpret from one language to another.

Cooke (1996) makes a number of recommendations arising from his research. These include establishing clear guidelines for determining when interpreters should be provided, especially in cases where witnesses appear to speak English adequately; an acceptance from the court that interpreters in these cases must be allowed to explain cultural differences that may lead to cross-cultural miscommunication; an adequate Aboriginal interpreting service for areas with high concentrations of traditional Aboriginal populations; courses for Aboriginal people on Western cultural knowledge and courses for lawyers on Aboriginal culture and cross-cultural communication. Further research to ascertain whether any or all of these recommendations make a difference in cross-cultural communication is also needed. As with the previous studies quoted above, research into Aboriginal court interpreting also needs to be further substantiated with larger samples and with different indigenous cultures and experimental methodologies.

\subsection{The interpretation of style and register in witness testimony}

In line with the research into the language of courtroom questions as explained above, much research has been conducted into the effect of the way witnesses present their answers, highlighting the fact that it is not only the content of the answer that is important when forming an impression of a witness, but also the way such information is presented. This has been found to relate to what is vaguely described as speech style, register or form (O’Barr 1982; Giles \& Powesland 1975). The seminal work by O'Barr and his colleagues found that a series of speech features made a speech style powerless and the absence of the same features made it powerful. These features included hesitations, hedges, fillers, discourse markers such as 'well' to commence a response, backtrackings and the overuse of politeness markers. The rationale behind the labels was based on their results of experimental studies which showed that speakers whose speech included a high percentage of the powerless speech features were rated by mock jurors as being significantly less credible, convincing, trustworthy, competent and intelligent than those whose testimony presented the same content without those features. Most speakers of the powerful speech style were professionals and most speakers of the powerless style were working-class, a fact that also contributed to the choice of these labels. 
Berk-Seligson (1990) conducted a descriptive discourse analytical study of twenty-seven witnesses' testimonies interpreted by six different interpreters. First of all, she found that there was a tendency for interpreters to add many of the features of the powerless speech style to their English renditions. These included the addition of hedges, polite forms of address and hesitations, as well as additional explanatory material and the use of uncontracted forms. One such example of the transformation of a powerful into a powerless answer is illustrated in example 5.

\section{Example 5}

$\begin{array}{ll}\text { Attorney: } & \text { What kind of house is that? } \\ \text { Interpreter: } & \text { ¿Que tipo de casa es? } \\ \text { Defendant: } & \text { Es una casa chica. (It's a small house). } \\ \text { Interpreter: } & \text { Well, it's a small house. } \\ \text { (Berk-Seligson 1990:141) }\end{array}$

Through matched-guise experimental methods, Berk-Seligson isolated two powerless speech features, hedges and politeness markers, to ascertain whether they had an impact on the evaluation of witnesses in isolation. In one study, she presented two different interpretations of the original Spanish testimony which contained numerous hedges, to mock jurors. One interpretation maintained the hedges, the other omitted them. The general result showed that those who listened to the hedged interpretation were significantly more negative in their evaluation of the witness. However, those mock jurors who spoke Spanish revealed no significant differences between the evaluations of the interpreted hedged and unhedged versions. This result is very different from the result found by Hale (2004), which will be explained below. However, the methodology was also very different. Whereas Berk-Seligson asked the Spanish-speaking mock jurors to evaluate the witness through the interpretation, Hale, asked the Spanish-speaking mock jurors to evaluate the witness' testimony directly in Spanish, not through the interpreter in English. Berk-Seligson speculates that hedging is more acceptable in Spanish-speaking cultures but this is not corroborated by Hale's study. It may be possible that in Berk-Seligson's study, the Spanish-speaking jurors ignored the interpreted version and simply heard the Spanish version, hence there was no difference between the two versions.

The other feature isolated by Berk-Seligson was that of politeness markers interpreted from Spanish into English. Using the same experimental methodology as before, she presented witnesses' Spanish testimonies through two interpretations: one that kept the politeness markers present in the original, and the other that omitted them. The mock jurors again included Spanish speakers who understood both the original and the English versions. This complicated the analysis, as it is not certain how these mock jurors evaluated those witnesses, whether by listening to the Spanish version alone or by a combination of both. The results for the whole sample of jurors showed that the English interpreted version which included the politeness markers rated more positively on convincingness, competence, in- 
telligence and trustworthiness. However, for the Spanish-speaking jurors, the versions which included the politeness markers rated more positively only in terms of competence and intelligence, but not in terms of convincingness and trustworthiness. Berk-Seligson argues that despite the jurors' understanding of Spanish, their evaluations differ according to the performance of the interpreter. One can also speculate, however, that these jurors were probably rating the interpreter's, rather than the witnesses' competence and intelligence, as they could easily tell when the politeness markers were omitted. Further studies into the interpretation of politeness are needed, as politeness is not necessarily expressed to the same degree across languages by simply adding or subtracting politeness markers. For example, the use of the politeness maker "please" is rare in Spanish, and the use of the markers "señor/señora" does not carry the same degree of politeness as their English counterparts, as they are used much more frequently and mostly as attention markers. Similarly, other languages, including Spanish, do not necessarily use indirectness to express politeness in the same degree as English, and using direct requests does not necessarily imply impoliteness (see Wierzbicka 1985; Green 1989; Mir 1993; Hale 1997a).

In a similar line to Berk-Seligson's experimental studies, Hale (2004) conducted a multifaceted study into the interpretation of Spanish-speaking witness testimony in Australia, where instead of isolating each feature, all of them were included as a single speech style. Hale proposes that it is the combination of these features that has a significant impact on the evaluations, not each of them in isolation. That is, the higher the frequency of powerless features in the speech, the less favourable the evaluation of the witness will be. Firstly, using discourse analytical methods, she analysed the way Spanish-English interpreters interpreted the testimony of witnesses into Spanish in seventeen different court cases, with a total of 1379 answers. The results showed that, in general, interpreters added some powerless features to their interpretation and omitted others. For example, the interpreted versions had considerably more hesitations and grammatical errors than the originals, but considerably fewer repetitions, backtrackings, fillers, hedges and discourse markers. When the interpreters' performances were analysed individually, Hale found that some tended to add powerless features consistently, others tended to omit them and others both added them and omitted them arbitrarily. The ultimate result then, was not that interpreters consistently added or omitted powerless features, but rather that they did not systematically try to copy the speech style of the originals.

To ascertain the effect of such changes on the listeners, Hale conducted matched-guise experiments where different versions of the same testimony segments of four witnesses were presented to mock jurors. These included the original Spanish testimonies, which were presented to Spanish speakers for their evaluation; the original interpreted version, a polished version which removed all the powerless features and an unpolished, accurate version which reflected as faithfully as possible, the same features found in the original Spanish testimonies. The English versions were presented to English speaking mock jurors. The results showed that the polished, power- 
ful version elicited significantly better results on the evaluation of credibility, competence and intelligence, than all the other versions, consistent with O'Barr's (1982) results. When the interpreted versions were compared to the original Spanish versions, three of the interpreters improved the rankings, especially on credibility, but one produced worse results for the witness. When the data were checked against this particular interpreter, it was found that this was an interpreter who added powerless features and ungrammaticalities to the original. The most interesting result of the study was that the accurate, unpolished version, which mimicked the original style of the Spanish testimony as closely as possible, elicited almost identical results to the ones elicited by the original Spanish testimonies themselves. This clearly indicated that it is possible to achieve a very similar reaction in the listeners when hearing testimony through an interpreter, when the interpreter is faithful to both content and style. This is a significant study that should be replicated in other language combinations and using larger samples. Further refinements to the methodology could also improve the reliability of the findings.

\subsection{Pragmatics in court interpreting research}

Different aspects of pragmatic theory have been used to analyse interpreting data. One general definition refers to pragmatic meaning as the meaning of utterances beyond the word, determined by context, situation and participants. This has led interpreting researchers to argue against the myth of literal, word-for-word translations. Another more refined aspect of pragmatic theory is the concept of speech acts as originally proposed by Austin (1962). The separation of locutionary act, illocutionary point and force, and perlocutionary effect, are central to speech act theory and to court interpreting theory. Grice's (1975) cooperative principle, which comprises the observance of the maxims of quality, quantity, relevance and manner, has also been applied to the analysis of cross-cultural communication and interpreting research. Finally, issues of politeness based on Brown \& Levinson's (1987) and Leech's (1985) theories, have also formed the theoretical bases of some interpreting research.

It is important to understand which aspect of Pragmatics interpreting researchers are applying when discussing their findings. When referring to the need for interpreters to achieve a pragmatic equivalence between the original and the interpreted versions, a number of researchers argue for the need to understand the utterance at the discourse level, rather than at the word or sentence levels and at attempting to achieve a similar reaction in the listener as the original would (Berk-Seligson 1990/2002; Hale,1996, 2004; Krouglov 1999; Mason \& Stewart 2001, Rigney,1999). This is achieved by paying attention, firstly, to the pragmatic point or intention of the utterance, and then to its force and potential perlocutionary effect. The pragmatic point or intention can be very general. For instance, in the example provided by Mason and Stewart (see ex. 6), the daughter, who is acting 
as an ad hoc interpreter, understood the underlying pragmatic intention of her father's utterance, who, through an indirect speech act, implies a rejection of the offer made to him. It can therefore be argued that she maintained the pragmatic intention or point of the utterance. However, she did not maintain the other two aspects of the speech act, illocutionary force and perlocutionary effect, which are greatly reduced. The father's point was not to offer a polite indirect answer, as she did through her interpretation, but instead to be explicit about his discontent, as evidenced by his reprimand to his daughter for not interpreting accurately. The perlocutionary effect would have been that of insulting the other party, producing in return a similar aggressive reaction.

$\begin{aligned} & \text { Example } 6 \\ & \text { Father: }\end{aligned}$
$\begin{aligned} & \text { Digli che e un imbecille! } \\ & \text { (Tell him he's an idiot) }\end{aligned}$
(Maughter: $\quad$ My father won't accept your offer.

Maintaining only the illocutionary point of the utterance is not enough to constitute an accurate rendition. This is the trend that can be found in the study of Danish court interpreters conducted by Jacobsen (2002). Jacobsen states that the interpreters in her sample are more preoccupied with maintaining the pragmatic meaning of utterances than their literal meaning (Jacobsen 2002:33). What she is referring to, is the first layer of pragmatic illocutionary point only, where the interpreters understand what the person meant to say and then reproduce it in the way they see fit, regardless of whether these renditions match the originals in terms of illocutionary force or perlocutionary effect. This is evident in the changes found in their renditions, which include a simplification of complex language (or register shift), the changing of implicit information into explicit information and the rephrasing or repeating of their own renditions to ensure comprehension of the content (Jacobsen 2002:31).

Brennan (1999) found similar results in her study of three British Sign Language (BSL)-English interpreters in Scottish courts, most of whom had no training at all and very limited bilingual competence. The research used both ethnographic methods in the form of court observations, interviews and questionnaires, and discourse analytical methods of analysis of video taped interpreted proceedings. She found that at times, the interpreters provided answers that correlated to the pragmatic implicature of the original but which disregarded the propositional content completely. They paraphrased the responses, indicating "a meaning inferred by the interpreter from what the witness has signed (...) which cannot be said to represent an accurate translation of what has actually been signed" (Brennan 1999:238). The study also found a tendency for the interpreters to simplify terms from English into BSL, such as changing "assume" for "think", "effects" for "problems", or "incident" for "trouble", thus producing a register shift. When interviewed about these changes the interpreters stated they consid- 
ered these terms too difficult for the deaf witnesses to understand, although such equivalents exist in BSL. Sometimes, however, these interpreters tended to use "a more English influenced variety of BSL", a variety typically seen in religious contexts. When interpreting into English, the trend was to elevate the level of formality from casual to formal. These studies mostly corroborate those presented by Hale (1997b) in her study of register variations caused by interpreters in court, where the tendency was to raise the level of formality when interpreting from Spanish into English and lower it when interpreting into Spanish.

Using the cross-examination of Rosa Lopez from the O.J. Simpson trial, Mason and Stewart (2001) analyse the manner in which 'face' is interpreted, as expounded by Brown \& Levinson's (1987) theory of politeness. Using qualitative discourse analytical methods, Mason and Stewart look at the way the interpreter both reduces the face threatening force of Lopez' defensive answers or increases it by her inability to adequately translate into English the illocutionary force of the utterances. Example 7 illustrates one such alteration caused by the interpretation.

$\begin{array}{ll}\text { Example } 7 & \\ \text { Att: } & \text { So you have not made a reservation? } \\ \text { Int: } & +++ \\ \text { W: } & \text { No pero no voy a hacerlo no más salir de aqui (xxx) tiempo } \\ & \text { para salir. (waves arm) No voy a hablar a las diez/ a la una de la } \\ & \text { mañana ... (xxx). } \\ & \text { (No but I am going to do it as soon as I leave here (xxx) time to } \\ & \text { leave. I am not going to speak at ten/ at one in the morning...(xxx). } \\ & \text { But I will make it as soon as I leave here. } \\ \text { Int: } & \text { Okay. You have not made a/ } \\ \text { Att: } & \text { I can't call at 1:00 in the morning because the airlines are closed at } \\ \text { Int: } & \text { that time. I have to wait. }\end{array}$

Mason and Stewart (2001) explain that by omitting the initial "no" the interpreter is converting a cooperative answer from the witness, in terms of Grice's maxims, into an uncooperative one, which flouts the maxims of quality and quantity. Lopez admits to the proposition presented by counsel but also offers a justification which in turn implies that the question is unreasonable, as she could not be expected to make a reservation at such early hours. By doing this, she attacks the attorney. Mason and Stewart argue that a more pragmatically accurate rendition of the original would have needed the addition of the discourse marker "hardly" as in "I'm hardly going to phone at one in the morning...", supporting Hale's (1996) explanation of pragmatic equivalence which postulates that additions or omissions of this kind are commonly needed for pragmatically accurate renditions to ensue. Mason and Stewart's (2001) study highlights the differences in expressing politeness in English and Spanish, such as the higher frequency of the imperative, the use of the polite form of the second person pronoun in Span- 
ish, and the different levels of markedness achieved through the use of the personal pronoun. The study shows that the interpreter ignores these subtle features in her interpretation, and instead of interpreting pragmatically, she interprets semantically. For example, there is no difference in her interpretation of utterances which include the personal pronoun ' $y o$ ' and those which do not, when in fact the inclusion of the pronoun in Spanish makes the utterance more emphatic and requires either the use of stress or the addition of a marker such as 'firmly' in English to maintain the same pragmatic force.

The strength of this case study lies in the researchers' analysis of the difficulties associated with rendering pragmatically accurate interpretations and in particular in achieving the same illocutionary force. This study does not claim to describe the practice of all Spanish interpreters, but instead it uses the data of one interpreter to illustrate issues of cross-linguistic pragmatics. Further follow up research using surveys to canvass interpreters' own opinions regarding the difficulties identified by this study followed by experiments would be useful to shed further light onto these issues.

\section{Research into the expectations of the role of the court interpreter}

The other important type of research into community interpreting has looked at the way the participants of the interpreted interaction perceive the role of the interpreter and how this can conflict with their professional code of ethics. Although the majority of such research has concentrated on community interpreting in general or on medical interpreting (see Chesher et al. 2003; Pöchhacker 2000; Angelelli 2004), this section will highlight the relevant sections of the few empirical studies that make specific reference to court interpreting. Anecdotal evidence has indicated that interpreters are often confronted with conflicting expectations from the different parties, feeling pressured from all sides to conform to different roles. On the one extreme, the court tends to see them as robotic language switchers, performing a task that can easily be performed by a machine. On the other extreme, the minority language speakers tend to see them as their advocates and saviours. In the middle of these two extremes are the professional requirements of their code of ethics and their own self, exerting different types of pressures (see Mikkelson 1998; Morris 1999; Rudvin 2002, 2004; Angelelli 2004; Hale 2005). Much of this confusion arises from the unstructured nature of the profession, where interpreting services can be offered by people from a variety of backgrounds. On the one end of the spectrum are the highly trained, ethical professional interpreters who understand their role clearly and assert it in the interaction. On the other end, are the bilingual volunteers who act as ad hoc interpreters with no training, no knowledge of a code of ethics nor any understanding of the interpreter's role. Such disparity in the background of practising interpreters leads to very different and conflicting performances, thus creating major confusion in those who speak through them. 
A number of research studies have sought to empirically test the existing anecdotal evidence. This type of research follows mostly an ethnographic methodology, with elicitation techniques comprising questionnaires, interviews, focus groups and direct observations. The results of such research can be divided into three main branches: the perceptions of the service providers, of the service recipients and of the interpreters themselves.

\subsection{Perceptions of the service providers}

In a study of court interpreting in England and Wales, Fowler (1997) set out to ascertain what role was envisaged by the court personnel for interpreters. Her methodology included ethnographic observations as well as interviews with individual personnel. She reports that all of the magistrates expected interpreters to be unobtrusive, drawing as little attention to themselves as possible. However, they also acknowledged that they drew attention to the interpreter by not speaking directly to the witness but through the interpreter using the third person, as in "tell him that", and by expecting the interpreter to solve any communication breakdowns that may occur. These magistrates expected interpreters to act impartially, however, they also expected them to maintain a "warm" and "helping" relationship with the defendants. Fowler states that they found it difficult to understand this paradox and speculates that this contradiction may be due to the fact that in the United Kingdom, magistrates are neither lawyers nor linguists (Fowler 1997).

Ibrahim and Bell (2003) report the findings of a nationwide survey of 152 Malaysian court officers, registrars, judges and magistrates. Court interpreters in Malaysia are public servants employed by the court and as such take on the roles of clerical staff and paralegals as well as of interpreters and translators. Among those extra roles imposed on Malaysian court interpreters are: setting hearing dates, reading and explaining charges, assisting the accused when unrepresented, and performing all other duties as requested by the court. These interpreters are unqualified and untrained as interpreters/translators, administrative staff or lawyers, yet they are expected to perform all of these complex tasks, receiving remuneration equivalent to a shop assistant's. When questioned about this practice, $81 \%$ of court personnel acknowledged that over $50 \%$ of interpreters' time was spent in duties other than interpreting, but $63 \%$ believed this was appropriate (Ibrahim \& Bell 2003:219). Such a result demonstrates a lack of awareness of the complexities of court interpreting and the need for specialist training and adequate remuneration.

The question of how and when interpreters should convey cultural differences in the course of their work has been discussed anecdotally, but has not been the topic of much empirical research. Although the topic has been included in debates about the role of the interpreter, little research has been conducted to ascertain the frequency of instances that require the intervention of the interpreter to clarify cultural issues, the types of cross-cul- 
tural issues that may lead to miscommunication, and the instances when cross-cultural differences can be adequately reflected in an accurate pragmatic interpretation. Kelly (2000) conducted a survey of 17 judges, 15 prosecutors, 21 defence attorneys and 3 legislators from Massachusetts, United States, to elicit their views regarding the interpreters' responsibility to convey cultural differences in the courtroom, the types of cultural differences that need to be communicated to the courtroom, and the expertise the interpreter should possess in order to be deemed qualified to offer such expert advice. With regards to whether interpreters should convey cultural differences at all in the courtroom, $53 \%$ of judges and $47 \%$ of prosecutors responded in the negative, while $48 \%$ of defence lawyers and $67 \%$ of legislators said "perhaps". These results demonstrate that approximately half of these court officials do not expect interpreters to explain cultural differences, but half of them do. Kadric's (2001, quoted in Pöchhacker 2004) survey of Austrian judges found that a high percentage of them also accepted interpreters explaining cultural references to the court. In Kelly's sample, the respondents were confused as to what "cultural differences" entailed, which is a concept that needs to be refined through further empirical research. The respondents who answered negatively to this question raised the concern that allowing the interpreter to explain cultural differences would imply shifting to a role of cultural broker, which in turn would undermine their impartiality. Another concern was the interpreter's lack of training and expertise as a cultural expert. The majority view was that major cultural differences should be addressed by an expert witness. Lawyers argued that interpreters should communicate important cultural differences to them during their conferences with their clients, rather than in the courtroom. This is, of course, a problem when a professional interpreter is not engaged for the pre-court visits.

When asked about what should be included among the cultural differences to be conveyed, the responses were varied. Gestures and customs were among the most popular answers. However, a high proportion left this answer blank or answered "other". Kelly here alerts the reader to the potential risk of stereotyping or overgeneralising, especially in languages that are spoken in many countries and regions whose cultures may be very different from each other, despite their sharing a language. Once again, this is an area worth investigating empirically.

The third question asked about the requirements interpreters need to meet to qualify them as bi-cultural experts. The results were not consistent across all respondents. For judges, experience was the most popular answer $(63 \%)$. For prosecutors, the completion of a translation program was the most popular answer (73\%); and for legislators, being a certified interpreter elicited the highest response $(100 \%)$. Kelly comments that interpreters should be recognised as bi-cultural experts, but this can only be warranted if interpreters are adequately trained and certified. She also adds that conveying cultural differences should not conflict with the code of ethics, which makes allowances for interpreters to do this at their discretion. 
Clearly, further research into this very important aspect of court interpreting is needed.

Hale (forthcoming) surveyed 21 Australian lawyers who were asked about different aspects of interpreting. In relation to role, $76 \%$ of lawyers believed that the interpreter's main responsibility was to interpret accurately. Some of the lawyers qualified their requirement for accuracy by stating "to the best of their ability" or "as much as possible", demonstrating an awareness that full accuracy may not always be possible. Some commented that interpreters needed to alert them to interpreting problems when these arose, and a number of them stressed interpreters should not add their own advice or opinion to the utterances.

When asked specifically about what they considered to be the role of the interpreter, $87.71 \%$ of lawyers chose the answer: "To ensure all utterances are interpreted accurately from and into English, leaving the responsibility for clarity to you and your client". Although a majority overall opted for the role as prescribed by the code of ethics, a significant minority chose the opposite, surrendering their responsibility for effective communication to the interpreter. This confusion was also reflected in their way of addressing their client. Only $42.86 \%$ of lawyers stated addressing their client directly, in the first and second persons. Consistent with this lack of a uniform understanding of the interpreter's role, only $38 \%$ of lawyers claim to explain the interpreter's role at the outset to their client.

\subsection{The interpreters' own perception of their role}

A section of Kelly's (2000) survey reported above, was directed at practising court interpreters, with a total of 14 responding. $50 \%$ of interpreters replied "perhaps" to the question whether they should convey cultural differences, with only $21 \%$ responding in the positive, and $29 \%$ in the negative. These results are very similar to those provided by the court officials, confirming an ambivalence on the part of practitioners about the appropriateness of offering such extra cultural information and, if so, when and how. In answer to the second question on what should be conveyed, all categories elicited high percentages (64\% customs, 57\% gestures, 50\% socioeconomic differences and $71 \%$ other), indicating that interpreters saw all of these as potentially valid aspects of cross-cultural differences. With regards to what qualifies them to provide cultural information, $71 \%$ opted for experience, with the next most popular answer being translation programs or other academic qualifications (57\% each). Such a high preference for "experience" may be explained by the fact that most practising court interpreters have not received formal interpreting training.

Looking at a related issue, Angelelli (2003) surveyed 293 conference, court and medical interpreters to discover their views regarding their role. Using a Likert-scale, interpreters were asked to rank on a scale from 1 
to 6 , whether they strongly agreed or disagreed with the following as being part of their role: "Aligning with one of the parties, establishing trust/facilitating mutual respect, communicating affect as well as message, explaining cultural gaps and establishing communication rules" (Angelelli 2003:19). Angelelli proposes that the higher the rankings for all components ( 6 represented "strongly agree"), the more "visible" the interpreter perceived $\mathrm{him} /$ herself to be. She found that conference interpreters produced the lowest values, followed by court interpreters and lastly by medical interpreters. These results are consistent with the settings. Conference interpreters work in a booth in isolation from the speakers; court interpreters work in a public, formal, constrained setting, where protocols and rules apply, whereas medical interpreters work in a private, more relaxed setting, where they have more freedom to interact. This study showed that there is a distinct difference in the way interpreters perceive their role according to setting. Further research looking at other aspects of role and at the consequences of the different applications of role should be conducted to further shed light onto this controversial issue.

\subsection{The minority speakers' perception of the role of the interpreter}

Very little research has been conducted into the minority speakers' perception of role or satisfaction rates with interpreting services, with a small number of studies conducted in the medical setting (Tellechea Sánchez 2005; Kuo \& Fagan 1999; Bischoff in this issue). The one major empirical study of the attitudes and expectations of non English speakers of the role of the community interpreter was conducted by Hale and Luzardo (1997), with results that directly relate to court interpreting. This study was conducted by way of scripted interviews over a period of three years. A total of 685 Arabic, Spanish and Vietnamese speakers were interviewed in their own language. The study found that only $43 \%$ of respondents considered interpreters as independent professionals, with the others perceiving them as compatriots, helpers or even social workers. Setting, language, age and level of education were important indicators of the different perceptions. The legal setting elicited the highest percentage $(55 \%)$ of responses indicating that interpreters were expected to be independent professionals and to abide by a code of ethics. The Spanish-speaking respondents also had the highest estimation of the level of professionalism of interpreters and their expectations were closer to those prescribed by the code of ethics ( $49 \%$ as opposed to $38 \%$ for Arabic and $42.9 \%$ for Vietnamese). Similarly, those respondents with a higher level of education and in the age groups between 21 and 50, expected interpreters to be university trained professionals more than those with only a primary education and in the $51+$ age group. These results show that even in the legal setting, only just over half of the respondents perceived interpreters to be professionals and understood their role as the one prescribed by a code of ethics. The other half of the respondents expected interpreters to act in a way that is considered unethical by professional interpreters. 
These survey studies have been very useful in empirically confirming much of the anecdotal evidence regarding role perceptions. Some of the studies are undoubtedly very limited due to small sample sizes and need to be further refined with larger data sets. Another weakness inherent in this type of research is the potential unreliability of the instruments, with questions that can cause confusion or bias. The speculative conclusions drawn by the authors of these studies are also at times difficult to substantiate from the qualitative results of the studies and therefore more research is needed to arrive at more generalisable results.

\section{Conclusion}

This contribution has provided an overview of the major empirical research into court interpreting. The scope of the article did not allow for a thorough review of all the research conducted into legal interpreting in general, nor on court interpreting in particular. However, the main themes and research methodologies have been covered. As legal interpreting research is in its infancy, much remains to be learned. Methodologies need to be further refined, data sets need to be expanded in terms of sample size and diversity of language combinations. There are noticeable gaps in some very important areas which need to be investigated. While there is a considerable body of knowledge about the current practice of court interpreters in some countries and language combinations, not much is known about the impact of such practices on the interaction. Legal interpreting training is also a highly neglected research area. The impact of training on interpreter performance, the type of training required to improve the performance, and general issues of curriculum design are all valid and important research questions that need addressing. Broader issues regarding the meaning of accurate interpreting and how it is achieved also need to be empirically tested. These are only a few areas among the limitless research questions that could be pursued. The current body of knowledge in court interpreting has provided an excellent base for further research to be conducted to continue to advance our knowledge. However, the impact of such research on improving the quality of interpreting services is not yet evident. Compulsory formal training is still not a reality for court interpreters, neither is compulsory certification or accreditation. Consequently, working conditions and remuneration levels continue to be below professional levels. It is hoped that the results of research will serve not only to obtain further knowledge, but also to inform and improve the practice and to effect social change.

\section{Bibliography}

Angelelli, C. (2004). Revisiting he interpreter's role. Amsterdam/Philadelphia: John Benjamins.

Angelelli, C. (2003). "The interpersonal role of the interpreter in cross-cultural communication. A survey of conference, court, and medical interpreters in the US, Canada and Mexico". L. Brunette, G. Bastin, I. Hemlin \& H. Clarke (eds), The Critical Link 3. Amsterdam/Philadelphia: John Benjamins. 
Atkinson, M. \& Drew, P. (1979). Order in court: The organization of verbal behaviour in judicial settings. London: Macmillan.

Austin, J. (1962). How to do things with words. Oxford: Oxford University Press.

Barsky, R. (1996). "The interpreter as intercultural agent in convention refugee hearings". The Translator, 2(1), 45-63.

Benmaman, V. (1995). "Legal interpreting by any other name is still legal interpreting". S. Carr, R. Roberts, A. Dufour \& D. Steyn (eds). The Critical Link: Interpreters in the community. Amsterdam/Philadelphia, 79-190.

Berk-Seligson, S. (1988). "The impact of politeness in witness testimony: The influence of the court interpreter". Multilingua 7(4), 411-39.

Berk-Seligson, S. (1990/2002). The Bilingual Courtroom: Court Interpreters in the Judicial Process. Chicago: The University of Chicago Press.

Berk-Seligson, S. (1999). "The impact of court interpreting on the coerciveness of leading questions". Forensic Linguistics 6(1), 30-56.

Berk-Seligson, S. (2000). "Interpreting for the police: issues in pre-trial phases of the judicial process". Forensic Linguistics 7(2), 212-237.

Brennan, M. (1999). "Signs of injustice. The Translator 5(2), 221-246.

Brown, P. \& S. Levinson (1987). Politeness. Cambridge: Cambridge University Press.

Chesher, T., H. Slatyer, V. Doubine. L. Jaric, R. Lazzari (2003). "Community-based interpreting. The interpreters' perspective”. L. Brunette, G. Bastin, I. Hemlin, H. Clarke (eds). The Critical Link 3. Amsterdam/Philadelphia: John Benjamins, 273-291.

Conley, J, \& W.M. O'Barr (1990). Rules versus relationships. The ethnography of legal discourse. Chicago/London: The University of Chicago Press.

Cooke, M. (1998). Anglo/Yolngu communication in the criminal justice system. PhD thesis, University of New England.

Cooke, M. (1995). "Interpreting in a cross-cultural examination: an Aboriginal case study". International Journal of the Sociology of Language, V.113, 99-111.

Cooke, M. (1996). Aboriginal evidence in the cross-cultural courtroom. Eades, D. (ed.). Language in evidence. Sydney: UNSW Press, 55-96.

Danet, B. \& B. Bogoch (1980). "Fixed fight or free for all? An empirical study of combativeness in the adversary system of justice". British Journal of Law and Society 7(1), 36-60.

Eades, D. (1992). Aboriginal English and the law: Communicating with Aboriginal English speaking clients: A handbook for legal practitioners. Brisbane: Queensland Law Society.

Eades, D., S. Hale \& M. Cooke (1999). "Introduction”. Forensic Linguistics. 6(1), 1-5.

Fraser, B. \& L. Freedgood (1999). "Interpreter alterations to pragmatic features in trial testimony". Paper presented at the Annual meeting of the American Association for Applied Linguistics (March 6-9, 1999, Stamford, CT).

Fowler, Y. (1997). "The courtroom interpreter. Paragon and intruder?" S. Carr, R. Roberts, A. Dufour, D. Steyn (eds). The Critical Link: Interpreters in the community. Amsterdam/Philadelphia: John Benjamins, 259-270.

Gibbons, J. (2003). Forensic Linguistics. Malden/Oxford: Blackwell.

Giles, H. \& P. F. Powesland (1975). Speech style and social evaluation. London: Academic Press.

Green, G. (1989). Pragmatics and natural language understanding. Hillsdale: Lawrence Erlbaum Associates.

Grice, H.P. (1975). "Logic and conversation". P. Cole \& J.L. Morgan (eds). Syntax and semantics 3: Speech acts. New York: Academic Press, 41-58.

Hale, S. (forthcoming). Community Interpreting. Hampshire: Palgrave Macmillan.

Hale, S. (1996). "Pragmatic considerations in court interpreting". Australian Review of Applied Linguistics 19(1), 61-72.

Hale, S. (1997a). "Interpreting politeness in court: A study of Spanish-English proceedings". S. Hale \& S. Campbell (eds). Research, training and practice. Proceedings of the second Macarthur Interpreting and Translation Conference, Sydney: University of Western Sydney/LARC, 37-45.

Hale, S. (1997b). "The treatment of register variation in court interpreting". The Translator 3(1), 39-54.

Hale, S. (1999). "Interpreters' treatment of discourse markers in courtroom questions". Forensic Linguistics 6(1), 57-82.

Hale, S. (2001). "How are courtroom questions interpreted? An analysis of Spanish interpreters' practices". I. Mason (ed). Triadic Exchanges. Manchester: St Jerome, 21-50.

Hale, S. (2004). The Discourse of Court Interpreting. Amsterdam/Philadelphia: John Benjamins.

Hale, S. (2005). "The interpreter's identity crisis". J. House, M. R. Martin Ruano \& N. Baumgarten (eds). Translation and the construction of identity. Seoul: IATIS, 14-29. 
Hale, S. \& Luzardo, C. (1997). "What am I expected to do? The interpreter's ethical dilemma. A study of Arabic, Spanish and Vietnamese speakers' perceptions and expectations of interpreters". Antipodean. The Australian Translation Journal 1 (October): 10-16.

Ibrahim, Z. \& R. Bell (2003). "Court interpreting: Malaysian perspectives. L. Brunette, G. Bastin, I. Hemlin \& H. Clarke (eds). The Critical Link 3. Amsterdam/Philadelphia: John Benjamins, 212-222.

Jacobsen, B. (2002). Pragmatic meaning in court interpreting: An empirical study of additions in consecutively interpreted question-answer dialogues. $\mathrm{PhD}$ thesis, AarhusScool of Business.

Kelly, A. (2000). "Cultural parameters for interpreters in the courtroom". R. Roberts, S. Carr, D. Abraham \& A. Dufour (eds), The Critical Link 2: Interpreters in the community. Amsterdam/Philadelphia: John Benjamins, 131-148.

Kuo, D. \& M. Fagan(1999). "Satisfaction with methods of Spanish interpretation in an ambulatory care clinic. Journal of general and internal medicine 14, 547-550.

Krouglov, A. (1999). "Police interpreting: Politeness and sociocultural context". I. Mason (ed.). The Translator, 5(2), 285-302.

Leech, G.N. (1985). Principles of pragmatics. London/New York: Longman.

Liberman, K. (1985). Understanding interaction in Central Australia: An ethnomethodological study of Australian Aboriginal People. Boston: Routledge.

Loftus, E. (1979). Eyewitness Testimony. Cambridge(MA): Harvard University Press.

Maley, Y. \& R. Fahey (1991). "Presenting the evidence: Constructions of reality in court". International Journal for the Semiotics of Law V(1), 3-17.

Mason, I. \& M. Stewart (2001). "Interactional pragmatics, face and the dialogue interpreter". I. Mason (ed.). Triadic exchanges. Manchester: St Jerome, 51-70.

Mikkelson, H. (1998). "Towards a redefinition of the role of the court interpreter". Interpreting 3(1), 21-45.

Mir, M. (1993). "Direct requests can also be polite". Paper presented at $7^{\text {th }}$ annual international pragmatics conference, University of Illinois.

Morris, R. (1999). "The gum syndrome: predicaments in court interpreting". Forensic Linguistics. 6(1), 6-29.

O'Barr, W. (1982). Linguistic Evidence: Language, power and strategy in the courtroom. New York: Academic Press.

Ogle, R., A. Parkman \& J. Porter (1980). "Questions: leading and otherwise: a framework for judicial discretion", Judges Journal 19(3), 42-5.

Pöchhacker, F. (2004). Introducing Interpreting Studies. London/New York: Routledge.

Pöchhacker, F. (2000). "The community interpreter's task: self-perception and provider views". R. Roberts, S. Carr, D. Abraham \& A. Dufour (eds), The Critical Link 2: Interpreters in the community. Amsterdam/Philadelphia: John Benjamins, 49-66.

Pym, A. (1999). "Nicole slapped Michelle. Interpreters and theories of interpreting at the O. J. Simpson trial". The Translator 5(2), 265-283.

Quirk, R., S. Greenbaum, G. Leech \& J. Svartvik (1985). A comprehensive grammar of the English language. London/New York: Longman.

Rigney, A. C. (1999). "Questioning in interpreted testimony”. Forensic Linguistics 6(1), 83-108.

Rigney, A. C. (1997) "The Pragmatics of question/answer structures in a bilingual courtroom". Paper presented at the Conference of the National Association of Judiciary Interpreters and Translators, Seattle, USA.

Rudvin, M. (2004). "Professionalism and contradictions in the interpreter's role". Paper presented at the Critical Link 4 Conference in Stockholm, Sweden, 20-23 May 2004.

Rudvin, M. (2002). "How neutral is neutral? Issues in interaction and participation in Community Interpreting”. G. Garzone (ed.). Perspectives on Interpreting 33. Bologna: CLUEB, $217-$ 233.

Russell, S. (2004). “Three's a crowd: shifting dynamics in the interpreted interview”. Cotterill, J. (ed.). Language in the legal process. New York: Palgrave Macmillan, 111-126.

Tellechea Sánchez, M.T. (2005). "El intérprete como obstáculo: fortalecimiento y emancipación del usuario para superarlo". C. Valero Garcés (ed.). Traducción como mediación entre lenguas y culturas. Alcalá de Henares: Universidad de Alcalá de Henares, 114-122.

Wadensjö, C. (1997). "Recycled information as a questioning strategy: Pitfalls in interpretermediated talk. S. Carr, R. Roberts, A. Dufour \& D. Steyn (eds). The Critical Link: Interpreters in the Community. Amsterdam/Philadelphia: John Benjamins, 35-54.

Wadensjö, C. (1992). Interpreting as Interaction. On dialogue interpreting in immigration hearings and medical encounters. Linköping: Linköping University.

Walker, A. G. (1987). "Linguistic manipulation, power and the legal setting. L. Kedar (ed.). Power through discourse. Norwood (N.J): Ablex Publishing Corporation. 
Wierzbicka, A. (1985). "Different cultures, different languages, different speech acts". Journal of pragmatics $9,145-178$.

Woodbury, H. (1984). "The strategic use of questions in court". Semiotica 48(3/4), 197-228.

1 The questioning of a witness by the party who called him/her to give evidence ('direct examination' in the USA). 